This study investigated the prevalence and evolvement from diagnosis of cardiovascular risk factors (hypertension, obesity (BMI), dyslipidaemia, albuminuria) in an ethnically diverse population of children with Type 1 diabetes (T1D).

Methods The study included all children diagnosed with T1D attending three paediatric diabetes clinics in East London between 2005-2015. Clinical and demographic information was collected prospectively during routine check-ups. Linear longitudinal mixed effects modelling (growth curve analyses) were used to analyse the development of cardiovascular risk factors from diagnosis. Models were adjusted for age, gender, ethnicity, diabetes clinic, glycated haemoglobin $\left(\mathrm{HbA} 1_{\mathrm{c}}\right)$.

Results Of 565 children $60 \%$ were non-white, of whom 8\% were Bangladeshi and $8 \%$ from Somali backgrounds. Mean age at diagnosis was 8.5 years (0.9-19.4). Mean length of follow-up was 4.3 years $(0-10.8)$. There was variation between clinics in commencing screening, range $8.8-13.8$ years $(\mathrm{p}<0.001)$.

$33 \%$ of all measures demonstrated an unhealthy BMI, 15\% revealed microalbuminuria, 66\% were above lipid targets with $5 \%$ reaching treatment thresholds. The frequency of abnormalities before or after 12 years of age was unchanged.

Longitudinal modelling revealed mean increases in BMI $(0.6$ $\mathrm{kg} / \mathrm{m}^{2}, 95 \% \mathrm{CI}: 0.6$ to 0.7$)$, blood pressure $(1.8 \mathrm{mmHg}, 1.5-$ $2.1)$, total cholesterol $(0.05 \mathrm{mmol} / \mathrm{mol}, 0.03-0.06)$ and low density lipoprotein (LDL) $(0.2 \mathrm{mmol} / \mathrm{mol}, 0.01-0.04)$ per year from diagnosis for the entire cohort. $\mathrm{HbA} 1_{c}$ directly affected all variables other than albuminuria. Results from subgroup analysis in children over 12 years old were similar but not statistically significant.

There was significant ethnic variation: Annual increments were greater for Bangladeshi children's cholesterol and LDL $(0.38 \mathrm{mmol} / \mathrm{mol}, \quad 0.1-0.6$ and $0.32 \mathrm{mmol} / \mathrm{mol}, \quad 0.09-0.55$ respectively) and Somali children's BMI $\left(1.6 \mathrm{~kg} / \mathrm{m}^{2}, 0.7-2.5\right)$ compared to White.

Conclusions Levels of abnormalities were above regional and national averages in children of all ages. Somali and Bangladeshi children had less favourable profiles, which supports findings of increased cardiovascular risk in these ethnicities. Commencing screening in younger children and introducing tailored interventions for ethnic minorities with T1D may help reduce cardiovascular events in adulthood.

\section{G225(P) DISORDERS OF SEXUAL DIFFERENTIATION CLINIC, OXFORD, UK}

${ }^{1} \mathrm{P}$ Ahmed, ${ }^{2} \mathrm{R}$ Romero, ${ }^{3} \mathrm{~F}$ Ryan. ${ }^{1}$ Paediatrics, Barnet General Hospital, London, UK; 2Paediatric Surgery, John Raddliffe Hospital, Oxford, UK; ${ }^{3}$ Paediatric Endocrinology, John Radcliffe Hospital, Oxford, UK

\subsection{6/archdischild-2018-rcpch.220}

Aim Disorders of sexual differentiation (DSD) are a heterogeneous group of genetic disorders with a mismatch of chromosomal, gonadal and phenotypic sex. The John Radcliffe Hospital is one of the largest and few DSD centres in the country, providing a highly specialised multi-disciplinary team service. The aims were to analyse the patient cohort with DSD under the care of the hospital, including their diagnoses, medical and surgical interventions and ascertain the strengths of the DSD service provided, and how the service can be improved to meet UK guidance on a DSD clinic.

Methods A retrospective review was conducted from 20122016 to identify the diagnoses and medical and surgical interventions of the DSD patients. The DSD clinic service was compared with UK guidance.

Results 46 patients were identified with 28 males, 18 females and $91 \%$ of patients having attended the DSD MDT clinic at least once. The average age of patients was 7.5 years. The number of patients with a genetic diagnosis was $96 \%$ and of those with a confirmed diagnosis, the most common diagnoses were partial androgen insensitivity syndrome (27\%) and congenital adrenal hyperplasia (25\%). The majority of patients were diagnosed by ambiguous genitalia- $85 \%$. Endocrinological problems were identified in $43 \%$ of patients, requiring input in the form of hormone replacement. Surgical intervention was required in $89 \%$ of patients, with hypospadias repair being the most common procedure. Currently, the DSD clinic involves input from surgery/urology, endocrinology and psychiatry, in order to devise a clinical management plan, as per UK guidance. Further areas for improvement include an endocrinologist to act as 'clinical lead' for newborns, improved links to adult services and an annual MDT meeting to review and discuss the patients and review the DSD clinic performance.

Conclusions The DSD MDT clinic meets many of the UK requirements. Importantly, an MDT clinic allows families to retrieve all results in one day with liaison between specialties for holistic care, and minimises time taken off work and school thus improving attendance, whilst forming a support group in the waiting room. Therefore, despite being a costly service, it is certainly worth continuing.

\section{G226(P) COELIAC DISEASE SURVEILLANCE IN CHILDREN AND YOUNG PERSONS WITH TYPE 1 DIABETES-ARE WE COMPLIANT?}

S Shah, J Smyth, V Simpson. Paediatrics, Southern Health and Social Care Trust, Portadown, UK

\subsection{6/archdischild-2018-rcpch.221}

Aims To evaluate current practice with regards screening for coeliac disease (CD) in children and young people with type 1 diabetes (T1D) within our Trust and to compare it with the other 6 hospitals within in the region. This also includes ongoing surveillance practice for $\mathrm{CD}$ at subsequent follow-ups until the young person is transitioned into adult services.

To compare our practice with national and international guidelines. $^{1,2,3,4,5}$

To undertake cost analysis for various screening strategies.

Methods A complete list of all known T1D children and young persons within our Trust in 2017 was obtained. The upper age limit was restricted to 18 years. A pre-designed proforma was used to record demographic information including sex, current age, age at diagnosis and current coeliac status. We also recorded how often and what method was used to undertake coeliac surveillance. This was compared with national and international recommendations for CD in highrisk groups.

Simultaneously we sent out a questionnaire to all other children and young people's services in the region regarding their screening and surveillance practices for CD in T1D children and young people. The results obtained were compared with our practice.

We undertook economic evaluation for various screening strategies 
Results Prevalence of CD in T1D children and young persons within our trust is $7.6 \%$

All hospitals within the region used coeliac serology rather than HLA specific alleles for initial screening for CD

There is regional variation regarding the frequency of ongoing surveillance for $\mathrm{CD}$ reflecting a national and international lack of consensus.

HLA allele testing at diagnosis is significantly more expensive even though it reduces eventual number of surveillance serology testing.

Conclusion All hospitals within the region are compliant with guidelines regarding screening for CD in T1D in children and young people at diagnosis

Although none of the hospitals used HLA specific alleles as suggested by joint Coeliac UK and BSPGHAN, ${ }^{3}$ we felt this was not cost effective and would only reduce a small number of repeat testing

We propose a unified region wide ongoing surveillance of once every 3 to 4 years.

\section{REFERENCES}

1. NICE guideline [NG20] September 2015. Coeliac disease: recognition, assessment and management.

2. NICE guideline [NG18] August 2015 [Last updated: November 2016]. Diabetes (type 1 and type 2) in children and young people: diagnosis and management.

3. Joint BSPGHAN and Coeliac UK guidelines for the diagnosis and management ofcoeliac disease in children.

4. European Society for Paediatric Gastroenterology, Hepatology, and Nutrition Guidelines for the Diagnosis of Coeliac Disease.

5. NASPGHAN Diagnosis and Treatment of Celiac Disease in Children.

\section{G227(P) A QUALITATIVE STUDY TO CAPTURE PARENTAL VIEWS ON THE TRANSITION OF CARE PROCESS FROM PAEDIATRIC TO YOUNG ADULT DIABETES SERVICES}

${ }^{1}$ AA Pandya, ' ${ }^{1} \mathrm{~L}$ Halpin, ${ }^{2} \mathrm{D}$ Barnes, 'M Libby, 'J Endean, 'L Rogers. 'Paediatrics, Maidstone and Tunbridge Wells NHS Trust, Tunbridge Wells, UK; ${ }^{2}$ Diabetes and Endocrinology, Maidstone and Tunbridge Wells NHS Trust, Tunbridge Wells, UK

\subsection{6/archdischild-2018-rcpch.222}

Aims An increasing number of children are presenting with long-term conditions that require transition into adult services. This can be a stressful and daunting prospect for both the child and their parents.

The aim of this pilot study was to collate the views of parents of children with Type 1 diabetes, whom would be transitioning in the near future. Eliciting their understanding and concerns relating to this process should help our transition team make appropriate changes, to ensure adequate support, preparation and explanations are given to current and future applicable families.

Methods An online anonymous survey (using Survey Monkey® software) was sent to 37 parents of children, aged 13 to 17 years, within our Paediatric Diabetes service.

Results We received 18 responses from a total of 37 parents. $56 \%$ of parents had not heard of transition of care services prior to this survey. $88 \%$ were unsure about what transition entailed, and in a free-text box expressed concerns about a lack of knowledge regarding this process. $72 \%$ of parents felt that transition of care had not been appropriately discussed $100 \%$ wanted more information. $72 \%$ of responders would appreciate a group transition meeting with other families, whom are also soon to transition.
Conclusions Our Paediatric Diabetes service is not adequately discussing and involving patients and parents in transition of care from an early stage, which is causing parental concern. All responders requested more information about the process of transition. Further education should therefore be provided to applicable parents and patients, including the opportunity to attend group meetings, which will allow for additional peer-support.

Limitations of this pilot included a low response rate (49\%), with only the views of parents being obtained and considered. We therefore plan to replicate this qualitative survey in February 2018, after a collaborative parent and patient transition evening, with the aim to capture both parental and patient views. Furthermore, we plan to use our experiences and feedback to assist with the development of other transition services with our Trust and the local Diabetes Network.

\section{G228(P) PAEDIATRIC TO YOUNG ADULT TRANSITION DIABETES SERVICE EVALUATION PROJECT}

${ }^{1} \mathrm{~N}$ Prathivadi Bhayankaram, 'UA Nayak, ${ }^{1} \mathrm{G}$ Varughese, ${ }^{2} \mathrm{P}$ Raffeeq. ${ }^{1}$ Department of Diabetes and Endocrinology, Royal Stoke University Hospital, Stoke on Trent, UK; ${ }^{2}$ Department of Paediatrics, Royal Stoke University Hospital, Stoke on Trent, UK

\subsection{6/archdischild-2018-rcpch.223}

Aims To explore any glycaemia changes from paediatric to young adult transition; non-attendances to young adult clinics and impact on diabetes related admissions.

Methods Data on adolescents with diabetes who went into young adult service from January to December 2016 was reviewed. $\mathrm{HbA}_{1 \mathrm{c}}$ at the last paediatric clinic (PC), transition clinic (TC) and first young adult clinic (YAC) appointments were collected. Comparison between group means was done by ANOVA and paired t-test; the differences between frequencies/proportions by chi-square test and for statistical significance $\mathrm{P}$ value of $<0.05$ was used.

Results Demographics of the cohort $(n=23)$ : males 43\%; Caucasian 100\%. Age when diabetes diagnosed $8.0 \pm 4.5$ years (mean $\pm s d)$. Age at last PC and the first YAC: $17 \pm 0.3$ and $18.1 \pm 0.4$ years respectively. $\mathrm{HbA}_{1 \mathrm{c}}$ at $\mathrm{PC}$ correlated significantly with the $\mathrm{HbA}_{1 \mathrm{c}}$ in the YAC $\left(\mathrm{r}=0.78, \mathrm{r}^{2}=0.61\right.$; $\mathrm{p}=0.001) . \mathrm{HbA}_{1 \mathrm{c}}$ was higher at YAC compared to that at the last $\mathrm{PC}$ visit $(88.4$ vs. $79.4 \mathrm{mmol} / \mathrm{mol} ; \mathrm{p}=0.001)$ but not significantly different to that in TC.

Non-attendance rate in YAC was $56.5 \%$ and diabetes related admission (DKA, Hypoglycaemia) occurred in $30.4 \%$. $\mathrm{HbA}_{1 \mathrm{c}}$ at YAC was significantly higher in those hospitalised (113 vs. $76 \mathrm{mmol} / \mathrm{mol} ; \mathrm{p}=0.007)$. Comparing those with non-attendances vs. those who attended the YAC their HbA1c 99.8 vs. $78.4 \mathrm{mmol} / \mathrm{mol}(\mathrm{p}=0.13)$. There were no differences in the age, age diagnosed diabetes and BMI in those with or without admissions for diabetes and those with DNA compared to non-attendances. Non-attendances to the YAC had higher rates of admission (38.5\% vs. 28.6\%).

Discussion Non-attendance to young adult clinics is associated with higher rates of hospitalisations for diabetes related complications and possibly associated poor glycaemia. In the transition from paediatrics to young adult diabetes services and change in responsibility from parents to child, patients may struggle to deal with compliance and service attendance. 